\title{
Rural Ecotourism -- Assistance in the Solution of the Development Dilemma about "Wonderful China"
}

\author{
Jiaxiang ${ }^{1}$ \\ ${ }^{1}$ Wuhan Business University,Wuhan ,Hubei,China
}

\begin{abstract}
Key Words: Wonderful China; Rural Areas; Ecotourism; Development
Abstract: In the course of development, the implementation of "Wonderful China" is faced with many problems. However, developing rural ecotourism could be an effective way to deal with it, which can not only provide more employment opportunities for farmers, but also promote the material civilization and spiritual civilization in rural areas. The construction of new countryside can be pushed forward so as to realize rural ecological civilization. First of all, from aspects of the economy, society and culture, the dilemma faced by the development of rural ecotourism in the background of "wonderful China"has been interpreted in this article. Then, how to effectively alleviate rural ecotourism after being involved in rural these areas is analyzed.
\end{abstract}

\section{Introduction}

the proposal of wonderful China is due to many problems encountered in the development of the countryside. For example, after the reform and opening up, the country has promoted the market operation mechanism to the countryside. However, due to the asymmetry of employment information and the comprehensive mechanization development of agriculture, farmers' income reduction and employment difficulties have been occurred. The increase of surplus rural labor force makes material and spiritual civilization extremely deficient in these rural areas. In order to help the construction of the new countryside, increase the income for the farmers and solve the difficulties faced by the wonderful China in some countryside, it can be said that promoting rural ecotourism would be an effective measure.

\section{Interpretation of the Dilemma in the Development of "Wonderful China"}

\section{(1) Economic Aspect}

Since the reform and opening up, the development of the market economy has become more and more active on the basis of the country's macroeconomic regulation and control. Subsequently, the market competition mechanism has been introduced into the countryside. However, because of the poor cultural level of the rural residents, the limited information acceptance as well as the asymmetry of employment information, the farmers can not adapt well to the market demand of employment. Also the excessive surplus of rural surplus labor force has caused a great negative impact on the self-sufficient rural economy. The original operation mode of small peasant economy has gradually lost its effect indeed. Under the trend of urbanization and rapid expansion, agricultural land is occupied as commercial land. As a result, the increase in production costs has led to a steep rise in the prices of agricultural products. Even if the country promulgated various policies to benefit farmers and normal people, the income of them continued to decline. Still, it is hard for them to get income just from land, which makes many farmers choose to leave their hometown for the work opportunities in cities. As a result, there are more and more absent parent, 
left-behind elderly and children emerged. In addition, with the development of economy and the progress of science and technology, the mechanization level of agricultural production methods has been improving. But the mechanization of production means no more labor is needed. Only a few technicians there can complete the agricultural production smoothly. This has caused a lot of surplus labor from the agricultural production line who was forced to leave for cities. On the one hand, the rapid development of cities and numerous dazzling jobs have attracted farmers to move from rural areas to cities. However, farmers will be restricted by low level of education, weak technical ability and unbalance of employment information after entering the city, which makes them often unable to get a job with good treatment and guarantee. On the contrary, they can only engage in hard work with cheap payment and long intense work, which are something of high investment and low returns. Even after leaving the countryside, the living conditions and income of farmers have not been improved significantly.

\section{(2) Social Aspect}

When rural labor is transferred to cities and towns, a large number of social problems will also arise. As the main labor force in the family, their going out to work will have some resistance to the normal functioning of the family. Then, the problems about left-behind elderly, women, children and many social security may occur frequently. First, men, who are the main labor force in the family, usually assume the responsibility of earning jobs and their living by work. While the women, less educated and less powerful than male, remain at home, who is responsible for the tasks of agricultural production, housekeeping, supporting for the elderly and taking care of the children. With the heavy workload increasing, the time for these people to go out for work is also reduced, with the increase in the burden of the body. Moreover, undesirable situations, such as husband and wife separated from each other for a long time, farm work and housework burdened on the wife alone, will also cause psychological stress to women. At the same time, as migrant workers are exposed to more updated life ideas and values, their lifestyle also changes to some extent. The long separation between husband and wife is bound to create contradictions and conflicts, which will lead to the breakdown of marriage. Second, without the parents' companionship and well education, these left-behind children not only have to help the elderly at home share household chores and farm work, but also may encounter with many mental health problems. Especially for children who are in adolescence, without proper parental guidance and restraint, their undeveloped mind can easily deviate from normal. They can not properly cope with the bad social temptations, thus playing truant, fighting, and indulging in the Internet may be happened. Third, the transfer of young and middle-aged labor force from rural areas to cities and towns has made the problem of providing for the aged in rural areas more and more serious. At the same time, the old people who were originally disadvantaged groups still had to shoulder the responsibility of taking care of children. Moreover, with the development of modern values, the pressure of moral public opinion on traditional support for the elderly has been gradually reduced. Coupled with the imperfections of the current support mechanism for the elderly, this often leads to the frequent negative news of elder abuse or not provided for support.

\section{(3) Cultural Aspect}

With the advancement of urbanization, urban culture has gradually infiltrated into the rural areas. Although the integration of foreign culture has greatly promoted the transformation of rural areas, it has also produced some negative effects. First of all, rural civilization lacks trust and advanced culture. As a large number of rural laborers pour into cities, all kinds of new media and information, even the negative ones, may brought back to the countryside. Farmers, who are in a rather weak position, can only passively accept cultural input. They can neither preserve the heritage of Chinese 
traditional culture nor completely accept the new culture. The result of the integration of these two kinds of cultures is that farmers can not establish rural culture suitable for their own way of life. Finally, the development of culture becomes deformities. Secondly, the infrastructure in rural areas is not perfect indeed. Because at present, the cultural industry that guides the rural and farmers' service has not yet developed into a system. Also, the cultural industry still takes the urban salaried class as the main audience while the rural cultural market has been ignored. Farmers can only passively accept cultural input. This also leads to the following problems in some township cultural institutions: shortage of personnel, limited funds and neglectful management. Grass-roots cultural organization can not be considered as a whole system. Finally, as a large agricultural country, the agricultural culture inherited from various dynasties was created by countless generations of farmers. The farming and life style of the peasants of the past dynasties are taught orally. However, due to the low level of education, the low quality of comprehensive culture as well as the backward conditions of entertainment in rural areas, farmers generally lack their cultural confidence. The appropriateness of traditional agricultural culture has not been realized by them, which has led to the fact that traditional agricultural culture has not been well protected.

\section{(4) Ecological Civilization Aspect}

Ecological civilization has always been the foundation for the development and progress of human society, which is the most scientific and harmonious coexistence among human being, substance and nature. And the most direct link between ecological civilization and tourism is the sharing of weal and woe between tourism and environmental protection. China is already the second largest economy in the world due to its rapid economic development. But at the same time, the domestic ecological environment problem has been criticized by the outside for a long time. Chinese tourism industry is developing rapidly. Actually, tourism has long been a pillar industry at all levels of the government. Rural tourism is an important way for the government to solve the imbalance between urban and rural development in recent years. However, the negative impact on rural environment seems endless to us. In the area of tourists, the uncivilized behavior of individual tourists not only brings negative influence on the overall image of tourists, but also brings bad impact on the popularization of civilized tourism. In terms of management, more emphasis is placed on how to develop, but not on adequate protection of the ecological and cultural environment. For example, only the construction of laws and regulations has been taken seriously, but the implementation has not been effectively carried out; The management of results has been emphasized, but process management has been ignored; The propaganda of ecological civilization has been emphasized, but the education of ecological civilization has been neglected.

\section{Rural Ecotourism: A Way to Relieve the Plight of "Wonderful China"}

\section{(1) A Case about Problems Encountered in the Transition Period of a Villages}

Taking Tianlong village as an example, after the reform and opening up, the village, which has long adhered to the self-sufficient small farmers' economic operation model, has suffered an unprecedented impact. First, agricultural income has gradually decreased. Although agricultural production has been fully mechanized at present, the increase in the cost of technology has also lead to the input cost increase of agricultural production. The price of agricultural products can only be raised within a narrow space. And agriculture is difficult to achieve great development. All of these have contributed to the income of farmers unable to improve. Coupled with the increase in the number of people, more people and less farmland, the contradiction between people and land is becoming increasingly acute. Secondly, in the past, some villagers in Tianlong village would 
choose to take some small business as a channel of income improvement. But with the integration of market economy into rural life, such a traditional convention market is hard to maintain. All kinds of commercial stores have gradually replaced the past small shops. Moreover, for most farmers, the weak capital reserves are not enough to expand the scale of larger business operations, so the incomes of business villagers are also decreasing. Finally, due to the difficulty of maintaining the traditional small peasant economy in rural areas, small-scale commercial operations have also been affected. In addition, the limited farmland can not take care of all the labor force. As a result, the surplus labor force in the village is increasing. At this point, most villagers choose the only way to get rid of this dilemma, that is, to leave for the cities to work. In fact, the general education level of villagers is rather low than the local. And the comprehensive cultural quality of them is insufficient. Therefore, they do not have any professional skills. Lacking competitive advantage in market competition, they can only choose the manual labor that is heavy with rare returns. In general, this income is no higher than that in rural areas. On the other hand, because of the living in the bottom of urban life, the quality of life is not guaranteed for them. Also, living conditions are bad because they can not get satisfactory service in personal, medical, educational, transportation and other aspects. Besides, these economic problems have also produced more social problems. The first to bear the brunt is the issue of the women left behind. After the husband, as a young and middle-aged laborer, went out to work, the rural women took the responsibility of taking care of the family alone. They not only have to do all the housework, including taking care of trivial matters, supporting the elderly, educating their children, but also undertake a large number of agricultural production activities. In the face of high intensity labor, women's physical strength is unbearable. And they can not operate agricultural machinery without systematic vocational training. Therefore, these problems, such as low efficiency of agricultural production in rural left behind women, insufficient knowledge popularization intensity, are urgently needed to be solved.

\section{(2) Mitigation of Problems after Rural Ecotourism Intervention}

Firstly, with the rise of rural tourism, great changes have taken place in the rural economy. Not only did the villagers increase their economic income, but they also benefited from the surrounding areas of tourism villages. After the Eighteenth National Congress of the CPC, Tianlong village began to develop rural ecotourism vigorously. On the whole, this has led to the increase in the income of the whole village, with the economic income of the local farmers also been promoted. This result is mainly due to the prosperity of the tourism industry, which provides a large number of jobs for farmers. Many villagers began to engage in tourism related work. Comparing the income of farmers before and after the development of rural ecotourism, we will find that the economic income grows faster, especially the farmers who are employed by tourism companies. Their income consists of salaries, performance and year-end awards, as well as extra profits due to percentage of peak travel. In addition, the local natural environment and customs did not deteriorate along with the vigorous development of the tourism industry. For the surrounding areas of these tourism villages, the changes in the rural industrial structure also provide farmers with more new ways to get rich. They no longer rely solely on farming and animal husbandry. Instead, accommodation, catering and intermediary services have become ways to improve their lives. The development of rural ecological environment and economy has made the tax revenue increased sharply, which has further promoted the increase of government revenue. Since the development of the economy, it has increased the per capital monthly wages of the village cadres, stimulated the enthusiasm of the cadres and reduced the financial burden of the higher authorities. Regional development is no longer dependent on funding.

Secondly, Since the rapid development of rural ecotourism, the rural industrial structure has 
changed. For example, Tianlong village tourism company has provided more employment opportunities for villagers. Women are no longer confined to heavy household chores and farm work at home. Instead, they work in the form of tour guides, salesmen and intermediary service professionals. The establishment of various agricultural and sideline products processing enterprises not only broadened the road to becoming rich in agriculture, but also resulted in sustained growth of farmers' income.

Thirdly, since the great development of rural ecotourism, Tianlong village has launched a comprehensive learning class in order to provide better tourism services. This includes Putonghua and English training, as well as tourism etiquette teaching, whose purpose is to strengthen the spiritual civilization construction of villagers, so that local villagers can use civilized and standard language to serve tourists. This has also improved the local public security situation and promoted the villagers' awareness of ecological civilization as well as environmental protection.

\section{Conclusion}

The proposal of "wonderful China" is to set up the idea that "ecological civilization is the cornerstone of all development". Originally, this is a solution to the serious inversion between China's economic development and the protection of the ecological environment. In the long run, the rural population will still occupy a large proportion of the population. In this context, the development and stability of the countryside is an important part of "wonderful China". The development of agriculture related affairs is the key concern of the country. And in the development of various rural affairs, rural ecotourism has won a excellent reputation for its green development concept. In recent years, the development of rural tourism has gradually occupied the mainstream, with more and more successful cases emerged. Therefore, we shall not hesitate to think that the development concept of rural tourism popularizing ecotourism is not only in line with the concept of "wonderful China", but also the best means to solve the dilemma of economic, social, cultural and ecological civilization in the development of "wonderful China" within these rural areas.

\section{Reference:}

[1] Jiayu Zhong, Siwei Liu, Xi Xiong. Analysis of Regional Differences in the Coordinated Development of Tourism and Urbanization [J]. Economic Geography, 2014, 34 (2): 187-192.

[2] Lina Shi, The Interactive Development Mode of New Rural Construction and Rural Ecotourism [J]. Ecological Economy (Chinese version), 2013 (11): 106-109.

[3] Yan Zhang, Han Dong, Yufeng Qiu, Research on the Development of Rural Ecotourism in the Context of New Rural Construction [J]. Agricultural Economy, 2013 (3): 81-82.

A brief introduction of the author: Jia Xiang, (September 1971 -), male, Han nationality, coming from Yuncheng, Shanxi, master degree. Research direction: tourism management, tourism education. Institution: Wuhan Business School. Zip code: 430056. Contact address: No. 816 Dongfeng Road, Wuhan economic and Technological Development Zone, School of tourism and hotel management, Wuhan business school. Telephone: 15927577178. 